NBER WORKING PAPER SERIES

\title{
THE NEW KEYNESIAN TRANSMISSION MECHANISM: A HETEROGENOUS-AGENT PERSPECTIVE
}

\author{
Tobias Broer \\ Niels-Jakob H. Hansen \\ Per Krusell \\ Erik Öberg \\ Working Paper 22418 \\ http://www.nber.org/papers/w22418 \\ NATIONAL BUREAU OF ECONOMIC RESEARCH \\ 1050 Massachusetts Avenue \\ Cambridge, MA 02138 \\ July 2016
}

We are very grateful for comments from Adrien Auclert, Lídia Brun, John Cochrane, Martin Eichenbaum, Jordi Galí, John Hassler, Hannes Malmberg, Karl Harmenberg, Jean-Baptiste Michau, Valerie Ramey, Søren Hove Ravn, Matthew Rognlie, Johan Söderberg, Karl Walentin, Ivàn Werning, Andreas Westermark, and seminar participants at the IIES, MIT Macro Lunch, Universitat Pompeu Fabra, Sveriges Riksbank, ENTER Jamboree in Mannheim 2015, UiO-NHH Macro Workshop at Norges Bank, SED Annual Meeting 2015, and EEA Annual Meeting 2015. All errors are our own. We are grateful to Handelsbanken's Research Foundations for financial support. The views expressed herein are those of the authors and do not necessarily reflect the views of the National Bureau of Economic Research.

NBER working papers are circulated for discussion and comment purposes. They have not been peer-reviewed or been subject to the review by the NBER Board of Directors that accompanies official NBER publications.

(C) 2016 by Tobias Broer, Niels-Jakob H. Hansen, Per Krusell, and Erik Öberg. All rights reserved. Short sections of text, not to exceed two paragraphs, may be quoted without explicit permission provided that full credit, including $\odot$ notice, is given to the source. 
The New Keynesian Transmission Mechanism: A Heterogenous-Agent Perspective

Tobias Broer, Niels-Jakob H. Hansen, Per Krusell, and Erik Öberg

NBER Working Paper No. 22418

July 2016

JEL No. E00,E32

\begin{abstract}
$\underline{\text { ABSTRACT }}$
We argue that a 2-agent version of the standard New Keynesian model-where a "worker" receives only labor income and a "capitalist" only profit income- offers insights about how income inequality affects the monetary transmission mechanism. Under rigid prices, monetary policy affects the distribution of consumption, but it has no effect on output as workers choose not to change their hours worked in response to wage movements. In the corresponding representative-agent model, in contrast, hours do rise after a monetary policy loosening due to a wealth effect on labor supply: profits fall, thus reducing the representative worker's income. If wages are rigid too, however, the monetary transmission mechanism is active and resembles that in the corresponding representative-agent model. Here, workers are not on their labor supply curve and hence respond passively to demand, and profits are procyclical.
\end{abstract}

Tobias Broer

IIES, Stockholm University

10691 Stockholm

Sweden

Tobias.Broer@iies.su.se

Niels-Jakob H. Hansen

IIES, Stockholm University

10691 Stockholm

Sweden

njharbo@gmail.com
Per Krusell

Institute for International Economic Studies

Stockholm University

10691 STOCKHOLM

SWEDEN

and NBER

per.krusell@iies.su.se

Erik Öberg

IIES, Stockholm University

10691 Stockholm

Sweden

erik.oberg@iies.su.se 


\section{Introduction}

There is significant recent interest in how inequality between consumers may affect the monetary transmission mechanism and how inequality is affected by monetary policy. Traditional New Keynesian (NK) models rely on a setting with a representative agent (RA) and thus by definition do not allow this topic to be analyzed. The RA setup is analytically very convenient, however, and the hope, perhaps, has been that its main conclusions are robust to extensions to multiple agents. ${ }^{1}$ With new analytical and computational tools available, a burgeoning literature is now beginning to explore the conjecture that most of the RA model's conclusions are indeed robust to consumer heterogeneity. This literature also explores the possibility that models with inequality can, under some conditions, give a richer and more realistic description of the monetary transmission mechanism. Very interesting analyses along these lines include Auclert (2015), Gornemann et al. (2016), McKay et al. (2015), and Kaplan et al. (2016), which all study rich heterogenous-agent (HA) settings with nominal frictions; Kaplan et al. (2016) coin the term HANK models to represent HA extensions to the NK model, thus making RANK an appropriate term of NK models using the RA assumption, with no pun intended.

Motivated by these analyses, the present paper points to a particular challenge that HANK models face when calibrated to the kind of inequality observed in the data. In the data, wealth is extremely concentrated; this has been documented extensively, with notable recent contributions by Wolff (2014), Piketty and Zucman (2015), Kuhn and Rios-Rull (2016), and Saez and Zucman (2016). Labor income is quite concentrated as well but much less so than is wealth. ${ }^{2}$ In this paper we analyze the very simplest extension of a NK model, namely, a model with two consumers aimed to represent "workers" and "capitalists", hence capturing what is arguably the key element of inequality in the data. ${ }^{3}$ We show that it has quite different properties than the cor-

\footnotetext{
${ }^{1}$ Very simple extensions to consider inequality have been shown to give near equivalence with the corresponding RA model in the context of real business cycle models; see the baseline results in Krusell and Smith (1998).

${ }^{2}$ The factor shares of income have not undergone major fluctuations, although they do exhibit some movements, especially recently; see, e.g., Karabarbounis and Neiman (2014).

${ }^{3}$ Our paper is related to the literature on monetary policy under limited asset market participationBilbiie (2008), Galí and Rabanal (2004), Buffie (2013), and Ascari et al. (2016)—that has centered around
} 
responding textbook RA model, where these two agents are simply merged into one household. We show, in particular, that the transmission mechanism depends greatly on the form of the nominal rigidity. A key finding is that it is especially challenging to make the 2-agent model generate active monetary transmission when hours are determined by the labor supply decision by workers. This is true under the baseline model with price stickiness. Under wage stickiness, however, where workers are de facto supplying hours mechanically over the cycle, the monetary transmission mechanism is active and resembles that in the corresponding RANK model.

Given the simplicity of the 2-agent model, our insights are easy to understand. In the textbook NK models, labor is the sole factor of production. With rigidities only in the goods market, workers respond to wages according to their labor supply curve. With the kind of preferences used in the macroeconomic literature-those where income and substitution effects cancel (see King et al. (1988)) —and without profit income accruing to workers, the income and substitution effect from changes in the wage level cancel out. ${ }^{4}$ Consequently, changes in the wage level will not be able to affect employment, and output becomes invariant to monetary policy. This does not mean, however, that monetary policy is neutral with respect to real variables. To the contrary, there are strong redistributional effects. As is well-known regarding this class of models (see, e.g., Christiano and Evans (1997)), profits respond countercyclically to monetary policy shocks, and from our 2-agent perspective this makes capitalists poorer while workers become richer in response to a surprise cut in the nominal interest rate. In sum, monetary policy cannot affect output, but there are effects on the distribution of consumption.

In contrast, under wage rigidity, workers are constrained to supply the quantity exploring the parameter region in which a Taylor-type monetary policy rule produces a determinate equilibrium. These papers also study new NK models with two classes of agents, reminiscent of our worker-capitalist model. Moreover, with different goals in mind, Walsh (2014) analyzes the impulse responses to a richer set of shocks in a similar worker-capitalist model that also includes taxes.

${ }^{4}$ The preferences in King et al. (1988) are often described as balanced-growth preferences as they deliver a balanced growth path for all macroeconomic variables under the restriction of a constant labor supply. Boppart and Krusell (2016) recently argue that a better approximation to the data is that hours fall at a constant (but small) rate and offer an enlargement of balanced-growth preferences that is consistent with this behavior and where income effects slightly outweigh substitution effects. Such preferences would only change our main conclusions here slightly (they would actually strengthen them). 
of labor demanded in the short run. A stronger degree of wage rigidity thus makes employment, and hence output, more determined by the response in consumption demand following the monetary policy shock. Consequently, the response of output to a monetary policy shock approaches that of the representative agent model for a sufficiently high degree of wage stickiness. Summing up, we see that the main results of the textbook NK model with price stickiness are not robust to introducing stylized consumer heterogeneity, but the same model with wage stickiness is; in the former, monetary policy cannot affect output, whereas in the latter it does.

Besides shedding light on how the transmission mechanism of monetary policy interacts with inequality, our results also highlight what we believe is an under-appreciated feature of the transmission mechanism in the standard RANK model with price rigidities only. In particular, both the countercyclical response of profits and their steady-state size play a key role for the employment and output response to monetary policy shocks in this environment. With preferences in the King-Plosser-Rebelo class (King et al. (1988)), it is the deviation of total income from labor income that determines the response of labor supply. When households receive profit payments lump-sum, such a deviation can occur: in response to an increase in goods demand and wages, firm profits fall, making the households poorer, thus generating the required increase in labor supply that meets the higher demand. Moreover, the larger is the steady-state profit share, the more potent is this channel. ${ }^{5}$

The paper proceeds as follows. In Section 2 we describe the representative-agent and the worker-capitalist versions of the NK model. In Section 3.1 we analyze the impulse responses to monetary shock under the assumption of flexible wages. In Section 3.2 we perform the same analysis under sticky wages. To make the exposition easier, we do not allow financial trade between the worker and the capitalist in the benchmark version of the worker-capitalist model we study. To verify that our results are robust to adding financial trade, we redo the impulse responses under this assumption in Section 4. Section 5 concludes.

\footnotetext{
${ }^{5}$ The standard RANK model often serves as a benchmark for business cycle and policy analysis in the NK literature (see, e.g., Lorenzoni (2009), Christiano et al. (2011), and Werning (2012)).
} 


\section{Two models}

To investigate the consequences of heterogeneity for monetary policy, we will compare the impulse-responses implied by a textbook version of the New Keynesian model to those of a 2-agent worker-capitalist model. In this section we describe the setups for these two models. Apart from the household sector, the models are identical in the way firms set prices and how the central bank sets the interest rate. Since these components are standard and well-known, we will describe them only briefly. ${ }^{6}$

A time period should be interpreted as a quarter of a year. As for notation, if not otherwise stated we will for any variable $X_{t}$ denote its steady-state value with $\bar{X}$, its $\log$ value with $x_{t}$ and its $\log$ deviation from steady state with $\hat{x}_{t}$. We will refer to the these deviations as "gaps". It is common to describe the log-linear equilibrium in terms of deviations from the flexible-price rather than in deviations from the steady state. In this paper, the only source of exogenous disturbances is shocks to the nominal interest rate, and since the model features long-run monetary neutrality, the two measures coincide.

We start by describing the common elements of both models, and then describe how the models differ in the setup of the household sector.

\subsection{Common elements}

The final good sector. There is a representative firm that produces the final good $Y_{t}$ by combining a continuum of intermediate goods $Y_{i t}$ through the Dixit-Stiglitz aggregator with elasticity of substitution $\epsilon_{p}$ :

$$
Y_{t}=\left(\int_{0}^{1} Y_{i t}^{\frac{\epsilon_{p}-1}{\epsilon_{p}}} d i\right)^{\frac{\epsilon_{p}}{\epsilon_{p}-1}} .
$$

The intermediate good sector. Intermediate goods are produced by a continuum of firms, indexed by $i$, with CRS technology $Y_{i t}=N_{i t}$. To allow for rigid wages (considered in a later section), we assume that $N_{i t}$ consists of a composite of differentiated

\footnotetext{
${ }^{6}$ For a detailed exposition, see Galí (2009). The only deviation from Galí (1999) Ch. 3 is that we assume a CRS production function whereas he assumes diminishing returns to scale. Assuming diminishing returns to scale complicates the expressions but does not affect the response of the worker-capitalist model to the textbook model in any meaningful way.
} 
labor inputs combined using a Dixit-Stiglitz aggregator with elasticity of substitution $\epsilon_{w}:$

$$
N_{i t}=\left(\int_{0}^{1} N_{i j t}^{\frac{\epsilon_{w}-1}{\epsilon_{w}}} d j\right)^{\frac{\epsilon_{w}}{\epsilon_{w}-1}} .
$$

Each firm $i$ takes the wages $W_{j t}$ as given. The intermediate goods producers set their prices to maximize expected discounted profits using the market discount factor $Q_{t}$. They can, however, only reset their prices with probability $1-\theta_{p}$ in every period. From these assumptions we can derive a log-linear relationship between inflation and the deviation of average marginal cost from steady state, that is, a Phillips curve:

$$
\pi_{t}^{p}=\beta E_{t} \pi_{t+1}^{p}+\lambda \hat{m} c_{t}
$$

where $\pi_{t}^{p}$ is the inflation rate in the goods market and $\lambda \equiv \frac{\left(1-\theta_{p}\right)\left(1-\beta \theta_{p}\right)}{\theta_{p}}$. Note that with CRS production technology, deviations in the average marginal cost equals the deviation in the real wage level, $\hat{m c_{t}}=\hat{\omega}_{t}$.

Wage evolution. There is also an accounting equation for the evolution of real wages

$$
\hat{\omega}_{t}=\hat{\omega}_{t-1}+\pi_{t}^{w}-\pi_{t}^{p}
$$

where $\pi_{t}^{w}$ is wage inflation.

Monetary policy. Finally, there is central bank that sets the interest rate according to a log-linear Taylor rule:

$$
i_{t}=\rho+\phi_{\pi} \pi_{t}+\phi_{y} \hat{y}_{t}+\nu_{t}
$$

\subsection{Households in the textbook model}

There is a unit mass of households, indexed by $j$, who only differ in the type of labor they provide. They derive utility from consuming a final good and disutility from working and can trade using a complete set of state-contingent assets. Each household can reset its wage with probability $1-\theta_{w}$ each period. A resetting household in period $t$ chooses a wage level $W_{t}^{*}$ to maximize its expected discounted utility conditional on not being able to reset this wage. The constraints the household faces includes the labor demand function from the intermediate good sector, (7): the hours choice is not free, 
given that the wage is set. The household also faces a budget constraint over the future relevant to not resetting the wage: (8). ${ }^{7}$ Specifically, the optimal wage then solves

$$
\max _{W_{t}^{*}} E_{t} \sum_{k=0}^{\infty}\left(\beta \theta_{w}\right)^{k}\left(\log \left(C_{j, t+k \mid t}\right)-\frac{N_{j, t+k \mid t}^{1+\varphi}}{1+\varphi}\right)
$$

s.t.

$$
\begin{aligned}
& N_{j, t+k \mid t}=\left(\frac{W_{t}^{*}}{W_{t+k}}\right)^{-\epsilon_{w}} N_{t+k} \\
& P_{t+k} C_{j, t+k \mid t}+E_{t+k}\left(Q_{t+k, t+k+1} B_{j, t+k+1 \mid t}\right) \leq B_{j, t+k \mid t}+W_{t}^{*} N_{t+k \mid t}+P_{t+k} D_{t+k} .
\end{aligned}
$$

Here, $N_{t+k} \equiv \int_{0}^{1} N_{j, t+k} d j$ is total hours supply, $W_{t+k}$ the average wage level, $P_{t+k}$ the price level, and $D_{t+k}$ real profit income all in period $t+k . Q_{t+k, t+k+1}$ denotes the oneperiod nominal bond price function at $t+k$ normalized by the corresponding conditional probability. ${ }^{8}$ The individual variables are $C_{j, t+k \mid t}, N_{j, t+k \mid t}$, and $B_{j, t+k \mid t}$ : real consumption, hours worked, and nominal bond income, respectively, in period $t+k$ and conditional on not having reset the wage after $t$. Thus, $E_{t+k}\left(Q_{t+k, t+k+1} B_{j, t+k+1 \mid t}\right)$ is the total nominal value of all assets purchased by the household to be carried into period $t+k+1$.

Under complete markets and separable utility, consumption is equalized across all households: $C_{j, t+k} \equiv C_{t+k}$. The first-order condition associated to the wage choice can be written

$$
\sum_{k=0}^{\infty}\left(\beta \theta_{w}\right)^{k} E_{t}\left\{C_{t+k \mid t}^{-1} \frac{W_{t}^{*}}{P_{t+k}}-M_{w} N_{t+k \mid t}^{\varphi}\right\}=0
$$

where $M_{w} \equiv \frac{\epsilon_{w}}{\epsilon_{w}-1}$. One can show that aggregate wage dynamics therefore follow

$$
W_{t}=\left[\theta_{w} W_{t-1}^{1-\epsilon_{w}}+\left(1-\theta_{w}\right)\left(W_{t}^{*}\right)^{1-\epsilon_{w}}\right]^{\frac{1}{1-\epsilon_{w}}} .
$$

Combining and log-linearizing (9) and (10) around steady state, we find the wage inflation Phillips curve

$$
\pi_{t}^{w}=\beta E_{t} \pi_{t+1}^{w}-\lambda_{w} \hat{\mu}_{t}^{w}
$$

${ }^{7}$ The overall consumer problem, which considers all contingencies, i.e., how different subproblems associated with different outcomes for the resetting process connect to each other, is specified in Erceg et al. (2000). We refer the reader to that paper for details.

${ }^{8} Q$ is a function of next period's state. 
where $\hat{\mu}_{t}^{w}=\mu_{t}^{w}-\mu^{w}$ is the log deviation in average wage markups $\mu_{t}^{w} \equiv \omega_{t}-\left(\varphi n_{t}+c_{t}\right)$ from their steady-state level $\mu^{w}=\log M_{w}$ and $\lambda_{w} \equiv \frac{\left(1-\theta_{w}\right)\left(1-\beta \theta_{w}\right)}{\theta_{w}} \frac{1}{1+\epsilon_{w} \varphi}$.

Notice that with fully flexible wages, i.e., under $\theta_{w}=0$, one can log-linearize the first-order condition (9) around the steady state to obtain

$$
\hat{\omega}_{t}=\varphi \hat{n}_{t}+\hat{c}_{t}
$$

The first-order condition with respect to consumption in the consumer's overall problem furthermore yields the usual Euler equation, which log-linearized around the steady state delivers

$$
\hat{c}_{t}=-\left(i_{t}-E_{t} \pi_{t+1}-\rho\right)+E_{t} \hat{c}_{t+1},
$$

where $\rho \equiv-\log \beta$ and $i_{t} \equiv-\log Q_{t}$.

Market-clearing conditions. The goods market clears when

$$
C_{t}=Y_{t}
$$

where $Y_{t}$ is total output. The state-contingent assets are in zero net supply, which implies that

$$
C_{t}=\int_{0}^{1} \frac{W_{j t}}{P_{t}} N_{j t} d j+D_{t} .
$$

Log-linearizing around the steady state, we find

$$
\begin{aligned}
\hat{c}_{t} & =\hat{y}_{t}, \\
\hat{c}_{t} & =\bar{S}\left(\hat{\omega}_{t}+\hat{n}_{t}\right)+(1-\bar{S}) \hat{d}_{t},
\end{aligned}
$$

where $\bar{S}=\frac{\bar{W} \bar{N}}{Y \bar{P}}$ is the labor income share of output in steady state.

\subsection{Households in the worker-capitalist model}

The worker-capitalist model features a unit mass of workers and a representative capitalist. As the words suggest, workers only have labor income and capitalists only have 
capital income (profits). ${ }^{9}$ In this model, we thus need to restrict agents' smoothing possibilities across dates and states in order for the analysis to fully capture heterogeneity and in order to remain in contact with the well-known settings in the macro-inequality literature. Markets can be restricted in several ways, however, and it is not entirely immaterial how the analysis is carried out. We have opted for a procedure where we first use the simplest setting allowing for meaningful analysis and then, as a robustness check, look at a more general structure. The simplest structure is one where capitalists have no access at all to smoothing and thus merely receive and consume profits. Workers, on the other hand, can trade in a complete set of state-contingent contracts amongst themselves. The equilibrium of this setting implies that workers' total consumption must also equal total labor income and that, within the worker group, there is full insurance. Moreover, the Euler equation is derived from workers. In the more general setting, we consider financial trade between workers and capitalist subject to trading costs and for costs such that there is a limited amount of active trade in response to shocks, the results from the simpler model are not significantly different from those of the simplest model. ${ }^{10}$ The analysis of financial trade is contained in Section 4.

Workers. The workers in the worker-capitalist model are very similar to the households in the standard model. They face the same maximization problem as does the representative household (6), with the exception that the budget set now does not in-

\footnotetext{
${ }^{9}$ The motivation for these stark assumptions is of course the very concentrated capital income (relative to labor income). The notion is thus that the simple model here is a short-cut for a more complex Aiyagari/Huggett-style model where some agents live mostly off of labor income and a small group of agents mostly off of capital income. The key qualitative difference is then that capitalists in such a richer setting would also work. However, they would work relatively little given their wealth and we conjecture that such a model would have similar features compared to the much more analytically tractable model studied here.

${ }^{10} \mathrm{An}$ alternative to the simpler model would be a specification where the worker is constrained and hand-to-mouth while allowing the capitalist to trade in the bond market. Under this assumption, however, the model does not have a determinate equilibrium under a standard Taylor rule, which would make a comparison of the worker-capitalist model to the textbook model difficult. The problem of indeterminacy, in the context of a similar model that also features hand-to-mouth households, is discussed in Bilbiie (2008).
} 
clude profits. That is, the budget set of the workers now reads

$$
P_{t+k} C_{w, j, t+k \mid t}+E_{t+k}\left(Q_{t+k, t+k+1} B_{j, t+k+1 \mid t}\right) \leq B_{j, t+k \mid t}+W_{t}^{*} N_{t+k \mid t},
$$

where we use the subscript $w$ on consumption to denote that of the worker. ${ }^{11}$ Working with the implied maximization problem leads to a modified wage inflation Phillips curve:

$$
\pi_{t}^{w}=\beta E_{t} \pi_{t+1}^{w}-\lambda_{w} \hat{\mu}_{t}^{w}
$$

where $\hat{\mu}_{t}^{w}=\left(\hat{\omega}_{t}-\left(\varphi \hat{n}_{t}+\hat{c}_{w t}\right)\right)-\mu^{w}$. Under fully flexible wages, (17) can be replaced by the standard intra-temporal optimization condition

$$
\hat{\omega}_{t}=\varphi \hat{n}_{t}+\hat{c}_{w t} .
$$

The Euler equation, in its log-linearized version, now reads

$$
\hat{c}_{w t}=-\left(i_{t}-E_{t} \pi_{t+1}-\rho\right)+E_{t} \hat{c}_{w t+1}
$$

The capitalist. The capitalist receives profits and consumes them hand-to-mouth. This way, the consumption of the capitalist simply reads

$$
C_{c t}=D_{t}
$$

Market-clearing conditions. The goods market clears when

$$
C_{w t}+C_{c t}=Y_{t}
$$

where $Y_{t}$ is total output. The state-contingent assets are in zero net supply, which implies that

$$
C_{w t}=\int_{0}^{1} \frac{W_{j t}}{P_{t}} N_{j t} d j
$$

Log-linearizing around the steady state, we find

$$
\begin{aligned}
\bar{S} \hat{c}_{w t}+(1-\bar{S}) \hat{c}_{c t} & =\hat{y}_{t} \\
\hat{c}_{w t} & =\hat{\omega}_{t}+\hat{n}_{t}
\end{aligned}
$$

where $\bar{S}=\frac{\bar{W} \bar{N}}{Y \bar{P}}$ is the labor income share of output in steady state.

\footnotetext{
${ }^{11}$ Capitalists do not work or use financial assets so no new subscripts are needed on such variables.
} 


\section{Impulse responses to a monetary policy shock}

We now consider the implications of an innovation in the monetary policy rate in the textbook model and the worker-capitalist model respond. We carry the comparison out under two different parameterizations (Table 1). In the first one, we assume that wages are fully flexible $\left(\theta_{w}=0\right)$ and that workers have no market power $\left(\epsilon_{w} \rightarrow \infty\right)$. This case corresponds to the simple 3-equation model presented in Galí (2009), Ch. 3 that is commonly used as a benchmark in the literature. In the second parameterization, we assume that wages are rigid. We take the parameter values from Galí (2009), Ch. 6, in which the resetting probability is set to $\theta_{w}=3 / 4$ (corresponding to an average wage spell duration of four quarters) and $\epsilon_{w}=6$.

\begin{tabular}{llll} 
Parameter & & Flexible wages & Rigid wages \\
\hline Discount factor & $\beta$ & 0.99 & 0.99 \\
Frisch elasticity & $\varphi$ & 1 & 1 \\
Output elasticity of labor & $\alpha$ & $1 / 3$ & $1 / 3$ \\
Subst. elasticity, goods & $\epsilon$ & 6 & 6 \\
Subst. elasticity, labor & $\epsilon_{w}$ & $\rightarrow \infty$ & 6 \\
Price adjustment parameter & $\theta$ & $2 / 3$ & $2 / 3$ \\
Wage adjustment parameter & $\theta_{w}$ & 0 & $2 / 3$ \\
Interest rule coefficient wrt. inflation & $\phi_{\pi}$ & 1.5 & 1.5 \\
Interest rule coefficient wrt. output & $\phi_{\pi}$ & $1 / 8$ & $1 / 8$ \\
Persistency of monetary policy shock & $\rho_{v}$ & $1 / 2$ & $1 / 2$ \\
\hline
\end{tabular}

Source: Galí (1999)

Table 1: Parametrization of models under flexible and rigid wages

The rest of the parameters are the same in both experiments and directly taken from Galí (2009), Ch. 3. Goods market prices are rigid with $\epsilon_{p}=6$ and $\theta_{p}=2 / 3$. For the preference parameters, we set $\varphi=1$ and $\beta=0.99$. For the Taylor rule, we set $\phi_{\pi}=1.5$ and $\phi_{y}=0.125$. Under both parameterizations, it is easily confirmed that the log-linear equilibrium systems have unique stable solutions.

For the monetary policy shock, we assume that innovations follow the process

$$
\nu_{t}=\rho_{\nu} \nu_{t-1}+\epsilon_{\nu t}
$$

with $\rho_{\nu}=0.5$. We feed a positive 25 basis-point shock to the two models. 


\subsection{Impulse responses under flexible wages}

In this section, we discuss the effects of a monetary policy shock under the parametric assumptions $\theta_{w}=0$ and $\epsilon_{w} \rightarrow \infty$. The impulse-response functions following the monetary policy shocks are plotted in Figure 1.
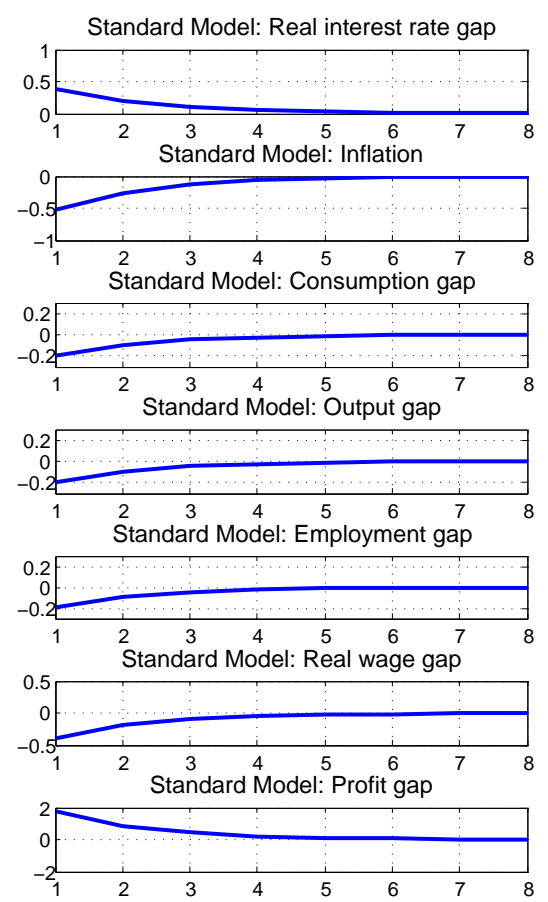
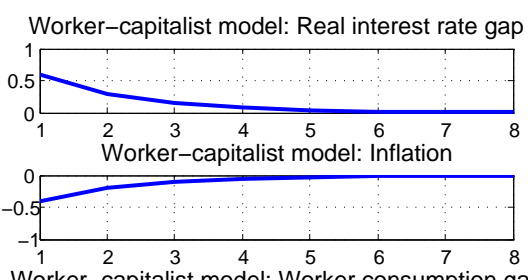

Worker-capitalist model: Worker consumption ga
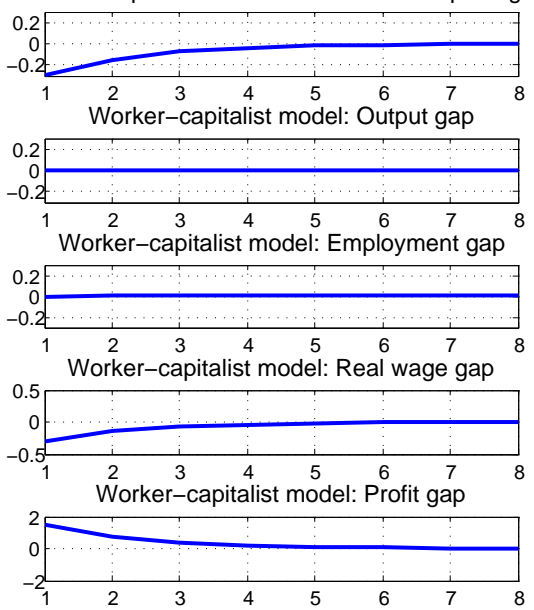

Figure 1: Equilibrium responses, measured as percentage deviations from steady state, to a positive 25 basis-point shock in the policy rate. Left panel: standard model; right panel: worker-capitalist model. Wage setting: flexible. Inflation and interest rates: yearly terms; other variables: quarterly terms.

As can be seen in Figure 1, the textbook and worker-capitalist models give qualitatively very similar responses in terms of the real interest rate gap, inflation, real wages, and profits. Thus, a part of the transmission mechanism appears very similar across models. However, in the textbook model, there is a substantial negative output and employment response, whereas in the worker-capitalist model, there is no response at all in these variables.

What explains these key findings? We start analyzing the responses in the workercapitalist model. Looking at the right-hand side of Figure 1, we see the standard response to the surprise increase in the nominal interest rate: the real interest rate increases. From the Euler equation (19), we then know that the worker consumption gap must start out negative to follow an upward-sloping path. This is because the worker responds to a downward-sloping interest rate path by moving consumption forward 
in time. The worker income gap must therefore follow the same path, as worker consumption equals worker income in equilibrium. Hence, either wages, hours worked, or both must initially fall. We see that only real wages fall; hours worked do not move.

The reason for the lack of response in hours worked is our preference specification: we use the KPR utility function, employed in most of the applied macroeconomic literature and originally proposed in King et al. (1988). These preferences are constructed so that hours have no trend in the long run, despite wage growth, and this is accomplished with an interior choice of hours only if income and substitution effects cancel. In a model where the consumer/worker only receives labor income, as in the present setting, this insight carries over straightforwardly. Formally, insert the market-clearing condition (22) into the intratemporal optimality condition (18):

$$
\begin{array}{ll} 
& \varphi \tilde{n}_{t}+\tilde{c}_{w t}=\tilde{\omega}_{t} \quad \text { and } \quad \tilde{c}_{w t}=\tilde{\omega}_{t}+\tilde{n}_{t} \\
\Rightarrow \quad & \varphi \tilde{n}_{t}+\tilde{\omega}_{t}+\tilde{n}_{t}=\tilde{\omega}_{t} \\
\Leftrightarrow \quad & \tilde{n}_{t}=0 .
\end{array}
$$

Clearly, regardless of the Frisch elasticity, hours will not change. ${ }^{12}$ Since hours worked are unresponsive, the fall in worker consumption matches the fall in wages. Because wages fall, so does the marginal cost of production, which leads to a fall in inflation and an increase in profits. The countercyclical response of profits, however, has no effect on equilibrium output since it is directly consumed by the hand-to-mouth capitalists. Notice, finally, that although aggregate consumption is unaffected by monetary policy, its distribution is: in response to a higher interest rate, the consumption of workers falls and that of capitalists increases.

Having explained the responses in the worker-capitalist model, it is now easy to understand the responses in the textbook model. As in the worker-capitalist model, the real interest rate gap increases, which leads to a fall in the consumption gap. There is also a fall in the real wage gap and an increase in the profit gap. However, hours worked and the output gap now decrease. To explain this, we again insert the market-

\footnotetext{
${ }^{12}$ With the slightly larger preference class derived in Boppart and Krusell (2016) and a parameter restriction implying that hours fall over the long run if wages grow, we would see hours rise in response to a drop in wages. Thus, a monetary policy tightening would make output go up, and hence make the transmission mechanism in the 2-agent model even more different than that in the textbook model.
} 
clearing condition (15) into the intratemporal optimality condition (12):

$$
\begin{aligned}
& \varphi \tilde{n}_{t}+\tilde{c}_{t}=\tilde{\omega}_{t} \quad \text { and } \quad \tilde{c}_{t}=\bar{S}\left(\tilde{\omega}_{t}+\tilde{n}_{t}\right)+(1-\bar{S}) \tilde{d}_{t} \\
\Rightarrow & \varphi \tilde{n}_{t}+\bar{S}\left(\tilde{\omega}_{t}+\tilde{n}_{t}\right)+(1-\bar{S}) \tilde{d}_{t}=\tilde{\omega}_{t} \\
\Leftrightarrow & \tilde{n}_{t}=\frac{1-\bar{S}}{\varphi+\bar{S}}\left(\tilde{\omega}_{t}-\tilde{d}_{t}\right) .
\end{aligned}
$$

Equation (23) allows us to make two related observations: hours can respond and the size of the response depends on the steady-state labor share. In particular, $\frac{1-\bar{S}}{\varphi+\bar{S}}$ is decreasing in the labor share $\bar{S}=\frac{\bar{W} \bar{N}}{\bar{Y} \bar{P}}$ on the unit interval and equals 0 when $\bar{S}=1$. If the labor share is 100 percent, KPR preferences imply that hours worked are unresponsive to monetary policy. When the labor share is less then 100 percent, the response of total income can potentially deviate from the response of labor income and so hours worked become responsive as well. The magnitude of the response is determined by how much the response of profits deviates from the response of real wages. To generate a response in output consistent with the path of the nominal interest rate and inflation, profits necessarily become countercyclical.

Intuitively, the increase in profits makes the representative household choose to work less: an income (wealth) effect. The effect is naturally decreasing in the steadystate profit share, which is about 17 percent in our parameterization. Moreover, the wage change has a direct effect on hours worked now since the worker also receives profit income, thus making the substitution effect stronger than the income effect. The fall in wages thus depress hours from this perspective as well.

The textbook model is thus capable of generating negative responses of employment and output to a positive innovation in the policy rate because 1) the households that supply labor also receive profit income and 2) because profit income responds less procyclically than do wages (in fact, the former is countercyclical in the model whereas the latter is procyclical). Although logically clear, this transmission mechanism does not seem empirically well grounded for two reasons. The first is the one emphasized here: few households have substantial non-labor income (see Table 2) and hence one would not expect workers to be much affected by movements in profits.

The second reason is that already pointed to in the literature: profits are strongly procyclical, not countercyclical, in the data and the available evidence is also that they fall after a monetary policy tightening (see Christiano and Eichenbaum (2005)). 


\begin{tabular}{lccccccc} 
Wealth percentile & $0-5$ & $5-20$ & $20-40$ & $40-60$ & $60-80$ & $80-95$ & $95-100$ \\
\hline Labor income & 92 & 83 & 91 & 89 & 89 & 81 & 55 \\
Financial income & 1 & 1 & 2 & 5 & 6 & 14 & 41 \\
Transfers & 7 & 16 & 8 & 6 & 5 & 6 & 3
\end{tabular}

Table 2: Data from the Survey of Consumer Finances (2004) for households aged 21-65. "Financial income" includes financial income, business income, and capital gains/losses. Source: Gornemann et al. (2016).

Thus, although the 3-equation textbook NK model offers very intuitive reduced-form responses to monetary policy that are aligned with intuition, the transmission mechanism whereby this is achieved is very hard to justify empirically. Fortunately, as we shall see, the rigid-wage model performs much better.

\subsection{Impulse responses under rigid wages}

In this section, we discuss the effects of a monetary policy shock under the parametric assumptions $\theta_{w}=3 / 4$ and $\epsilon_{w}=6$ while maintaining sticky prices parameterized as before. The impulse-response functions following the monetary policy shocks are plotted in Figure 2.

Before comparing the responses of the textbook and worker-capitalist model, we discuss how adding wage rigidities changes the impulse responses in the textbook model by comparing the left-hand side of Figure 2 to the left-hand side of Figure 1. Adding wage rigidities with $\theta_{w}=3 / 4$ to the textbook model changes the magnitude of the responses in several variables. Notably, it almost eliminates the response in real wages, as well as making the response of profits procyclical. The reason is that with rigid wage setting, nominal wages respond very little to the shock. Hence, nominal marginal costs of the intermediate goods firms respond only little. As a consequence, the response of inflation is also muted, but still sufficiently strong to almost completely close the real wage gap. As the real wage gap is almost zero, the movement of profits is solely determined by the movement in output, and thus profits respond procyclically.

Turning to the comparison between the textbook and the worker-capitalist model, we see that the responses to the monetary shock are almost indistinguishable. With an 

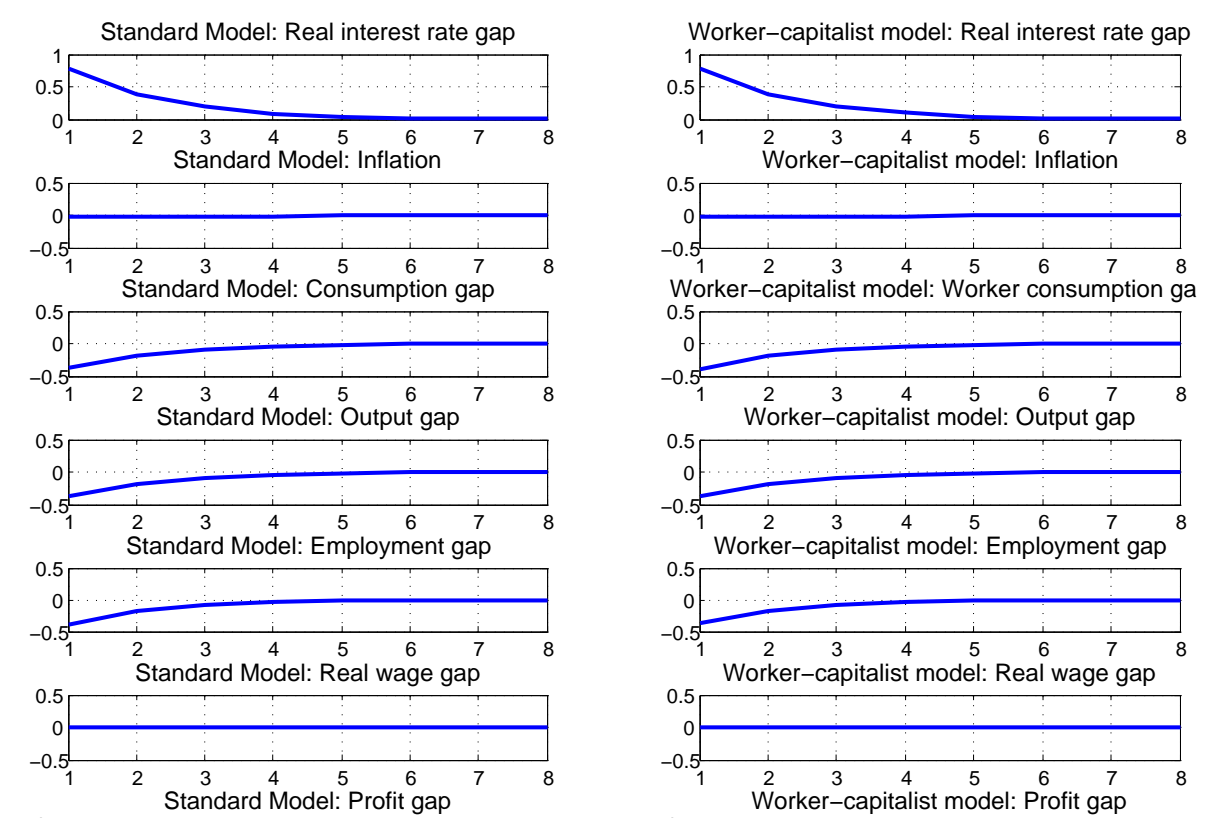

0.5
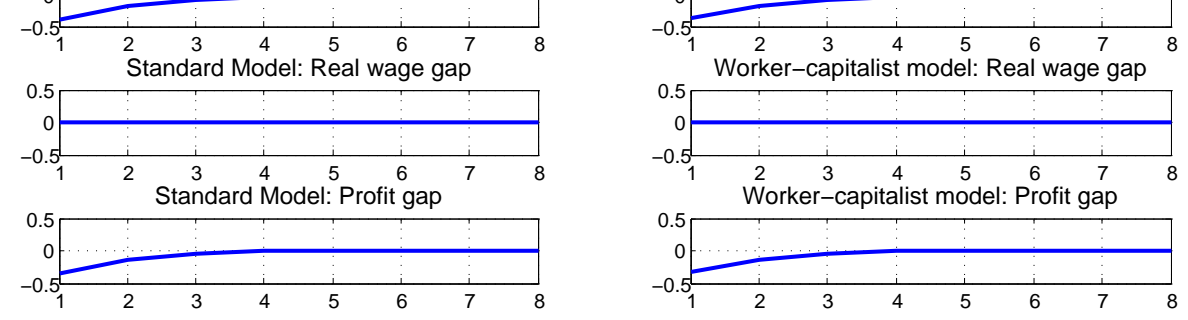

Figure 2: Equilibrium responses, measured as percentage deviations from steady state, to a positive 25 basis-point shock in the policy rate. Left panel: standard model; right panel: worker-capitalist model. Wage setting: rigid. Inflation and interest rates: yearly terms; other variables: quarterly terms.

average wage resetting duration of 4 quarters, the income and substitution effects matter less for the determination of hours worked at the shorter horizon. The majority of households (workers) are instead constrained to supply whatever labor is demanded from equation (7). Labor demand follows directly from consumption demand, as labor is the sole factor of production. In the textbook model, aggregate consumption demand follows from the real interest rate. And since profits constitute a small share of total income in the steady state (close to 17 percent) and respond procyclically, aggregate consumption demand in the worker-capitalist model behaves similar to that in the textbook model.

Assuming rigid wages thus seems to offer a solution to the implausible transmission mechanism in the textbook 3-equation model. In fact, the difference between the textbook and the worker-capitalist model is decreasing in $\theta_{w}$, which means that strength of this solution is increasing in the degree of wage rigidities. Whether the actual economies feature substantially rigid wage setting at the business cycle frequency is an empirical question that we do not evaluate here. At the very least, however, in light of our findings, to have accurate measures of the degree of rigidities in the labor 
market seems important for generating a plausible transmission mechanism with this class of models.

\section{Robustness: financial trade}

In the setup of the worker-capitalist model, we did not allow for financial trade between the workers and the representative capitalist. We made this assumption for reasons of tractability. In this section, we show that this model can be seen as an approximation to a model where the capitalist is allowed to trade a risk-free bond with the workers.

Without further assumptions, allowing the capitalist to trade in the bond market implies that the model becomes non-stationary. In response to a surprise increase in the nominal interest rate, we have seen that the response of real wages (when the nominal wage is fully flexible) is negative while the response of profits is positive. In equilibrium, the workers will therefore become indebted to the capitalist when allowing trade in bonds. The consumption-smoothing motive makes this indebtedness permanent, so that the capitalist has permanently higher consumption than the worker in response to the shock. Hence, linearization around a given steady state does not offer a way of analyzing the effects of shocks. To maintain stationarity when allowing for financial trade in the model we therefore assume that the capitalist faces quadratic bond-holding costs, which ensures that the capitalist holds zero financial wealth in the long-run equilibrium. This assumption is commonly used to close two-country international macroeconomic models; see, e.g., Schmitt-Grohé and Uribe (2003).

Thus, we change the capitalist problem described in Section 2 to

$$
\begin{aligned}
\max _{C_{c t}, B_{c t}} & E_{0} \sum_{t=0}^{\infty} \beta^{t} \log C_{c t} \\
\text { s.t. } & P_{t} C_{w t}+Q_{t} B_{c t} \leq B_{c, t-1}+P_{t} D_{t}-\frac{\zeta}{2} B_{c, t-1}^{2},
\end{aligned}
$$

where $B_{c t}$ is the capitalist's net purchases of risk-free bonds. Maximization yields an Euler equation, which we log-linearize around the steady state to find

$$
\hat{c}_{c t}=-\frac{1}{\sigma}\left(i_{t}-E_{t} \pi_{t+1}-\rho\right)+E_{t} \hat{c}_{c, t+1}+\zeta \bar{Y} \hat{b}_{c t},
$$

where $\hat{b}_{c t}$ is defined as $\hat{b}_{c t}=\frac{B_{c t}}{Y}$, i.e., the private debt-to-GDP ratio, where GDP is measured by its steady state value. 
The goods market clearing condition is now

$$
C_{w t}+C_{c t}+\frac{\zeta}{2} B_{c t-1}^{2}=Y_{t}
$$

As stated, in the steady state we construct, $\bar{B}_{c t}=0$. Thus, if we log-linearizing around the flexible-price equilibrium, we find that

$$
\begin{aligned}
\bar{S} \tilde{c}_{w t}+(1-\bar{S}) \tilde{c}_{c t} & =\tilde{y}_{t} \\
\tilde{c}_{w t} & =\tilde{\omega}_{t}+\tilde{n}_{t} .
\end{aligned}
$$

The rest of the worker-capitalist model is unaffected.

We have one more parameter to calibrate now: $\zeta$. Changes in the value of $\zeta$ have a larger impact on the aggregate responses when wages are flexible, with a countercyclical response in capital income and a procyclical response in wage income. We calibrate $\zeta$ focusing on this case. With higher values of $\zeta$, there is naturally less trade in bonds in equilibrium, converging to no trade as $\zeta \rightarrow \infty$; this limit case mimics the workercapitalist model in Section 2. At the other extreme, when $\zeta=0$, the model coincides with the standard representative-agent setting. We thus focus on an intermediate case, with $\zeta=4$, implying small amounts of intertemporal trade. For this case, the response to a 25 basis-point monetary policy shock amounts to a peak for the debt-to-GDP ratio of 0.099 percent. ${ }^{13}$

We feed in the same monetary shock as in the previous section. The impulse responses are plotted side by side with the responses in the worker-capitalist model without financial trade in Figure 3 and 4, for the parameterizations without and with rigid wage setting respectively.

As seen, the two models behave very similarly under flexible as well as rigid wages. In the case of rigid wages this is natural, since we have already seen that the workercapitalist model without financial trade behaves very similarly to textbook model. In the case of flexible wages, the similarity might be more surprising. However, because the adjustment costs limits the response of the debt-to-income ratio to 10 percent of GDP, worker consumption is still close to labor income every period. Hence, the determination of labor supply is similar to that in the model without financial trade. That is,

\footnotetext{
${ }^{13}$ For near-zero adjustment costs, as pointed out above, debt-to-GDP responses are extremely persistent. For the case we report on here, convergence rates are much faster and the debt-to-GDP ratio is back to (very close to) steady state within less than three years.
} 

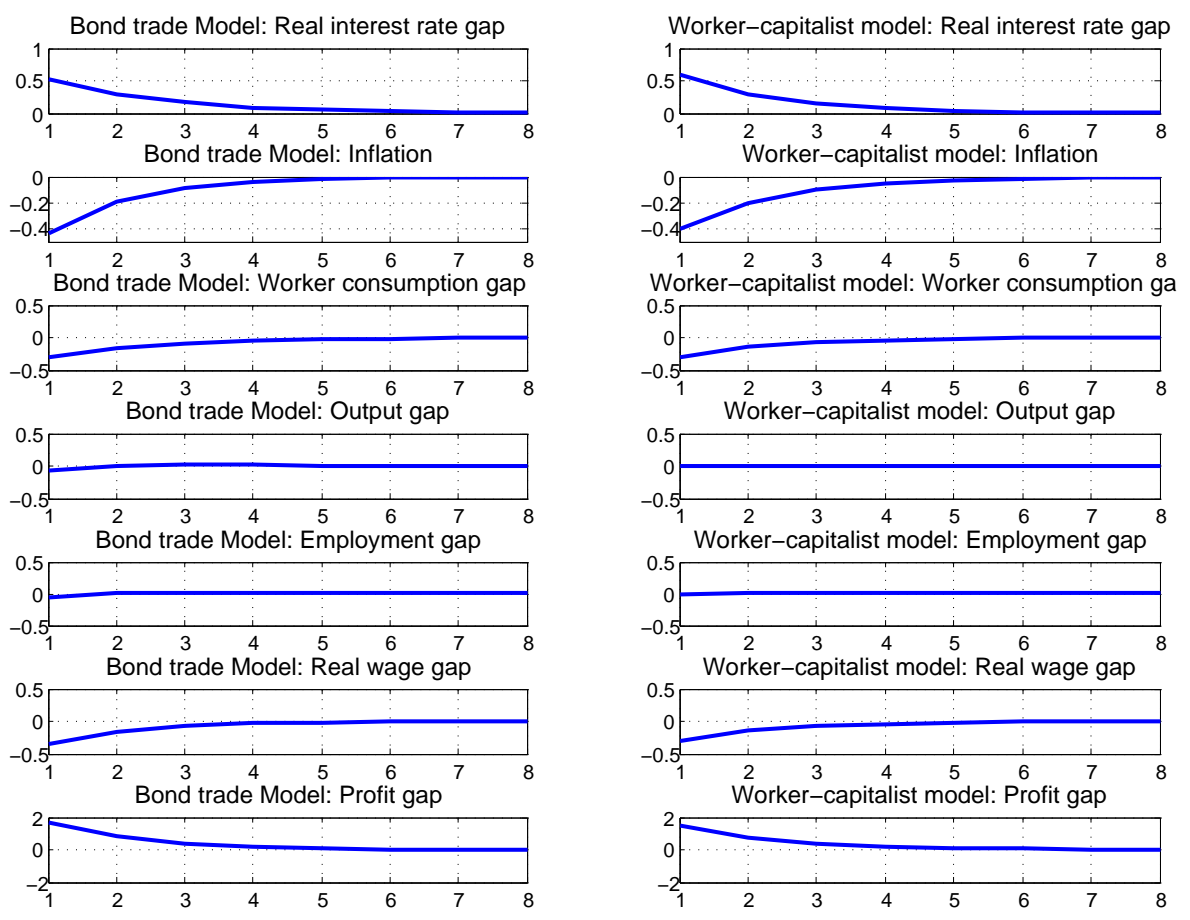

Figure 3: Equilibrium responses, measured as percentage deviations from steady state, to a positive 25 basis-point shock in the policy rate. Left panel: worker-capitalist model with bond trade; right panel: worker-capitalist model without bond trade. Wage setting: flexible. Inflation and interest rates: yearly terms; other variables: quarterly terms.

workers do not experience the positive income effect coming from the increase in profits and hence the income and substitution effects are still approximately of the same size, so that the responses of hours worked and output are close to zero. 

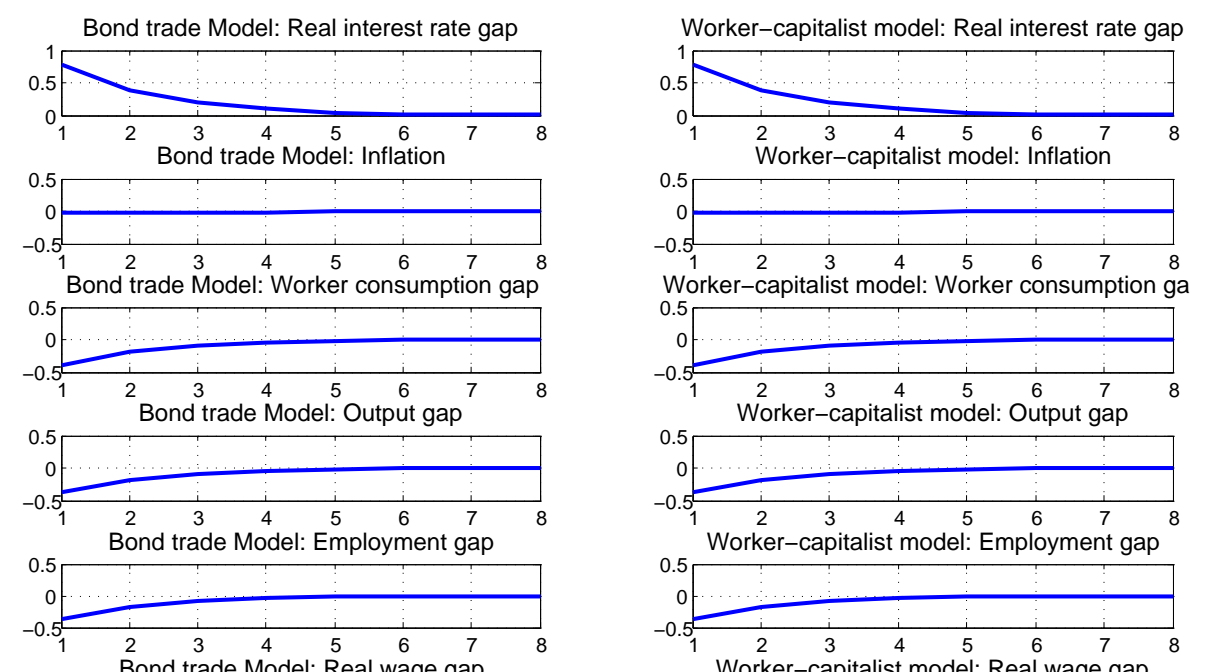

Worker-capitalist model: Employment gap
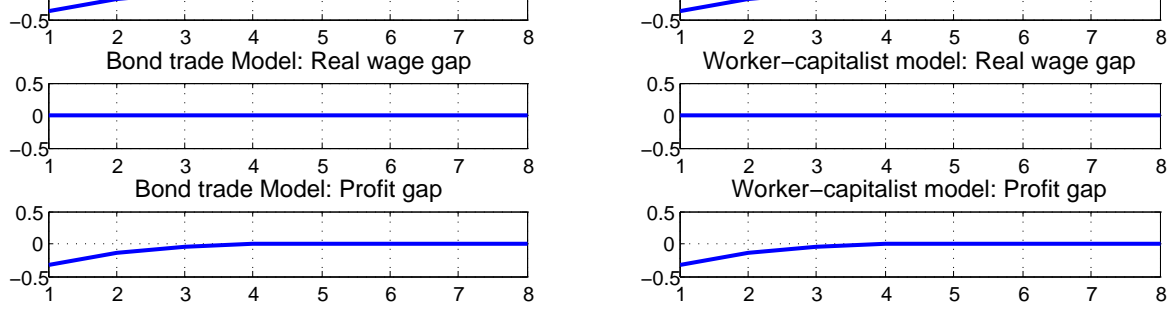

Figure 4: Equilibrium responses, measured as percentage deviations from steady state, to a positive 25 basis-point shock in the policy rate. Left panel: worker-capitalist model with bond trade; right panel: worker-capitalist model without bond trade. Wage setting: rigid. Inflation and interest rates: yearly terms; other variables: quarterly terms.

\section{Concluding remarks}

In this paper, we have discussed how income heterogeneity affects the impulse responses to a monetary shock in the New Keynesian framework. We have done so under two different assumptions regarding the source of nominal frictions. Our main conclusion from this analysis is twofold: (i) the benchmark textbook NK model is not robust to the introduction of stark and real world-like inequality; but (ii) the textbook NK model with added wage rigidity does show robustness. In the process, we also uncovered that the representative-agent model with only price stickiness, though allowing a reduced-form link from monetary policy to output that seems plausible, relies on a transmission mechanism that is implausible: in response to a lowering of the policy rate, profits fall, making workers poorer and hence enticing them to work harder.

In this concluding section, we briefly comment on how consumer heterogeneity of the kind considered here has other implications as well. In particular, we study the impulse responses to TFP shocks. After that, we discuss some possible directions for 
future research.

Let us thus first comment on TFP shocks. Galí (1999) has argued that the response of a TFP shock in the textbook NK model serves as an argument in favor of that model compared to the standard real business cycle (RBC) model. Specifically, the former generates a drop in hours worked in response to a positive innovation in TFP, while the later generates an increase. The response of hours to TFP shocks in the data has been subject to debate, but a number of studies find that hours fall in response to a positive productivity shock: Galí (1999); Francis and Ramey (2005); Basu et al. (2006). This Galí (1999) interprets as evidence in favor of the NK and against the RBC framework. ${ }^{14}$

Investigating the response of hours worked to a TFP shocks in the worker-capitalist model can help us understand what drives the response in the standard NK model. Without rigid wages, KPR preferences imply that hours are constant also under TFP shocks. ${ }^{15}$ So why do hours fall in the standard NK model? When productivity increases in that standard model, both wages and profits respond procyclically. Higher wages affect hours worked positively, as the substitution effect dominates the income effect, while the higher level of profits weighs in negatively on hours through the wealth effect they imply. On net, hours fall in the standard model because the latter effect dominates. This mechanism seems implausible as only few households have substantial non-labor income in their budget set. Because we find this transmission mechanism implausible, we are correspondingly skeptical toward the mechanism through which the standard NK model generates a countercyclical response of hours to TFP shocks. Rigid wages would, however, change the picture here as well.

Our main claims of this paper are of course confined to a specific class of NK models. It can thus turn out that representative-agent NK (RANK) models that only have stickiness in prices but that include other features not considered here lead to less implausible transmission channels. Obvious such features include physical capital, investment adjustment costs, and consumption habits. However, those other features are then crucial for the transmission mechanism and should therefore be in focus also in textbooks, in our view. Thus, the textbook RANK model with only price stickiness

\footnotetext{
${ }^{14}$ However, Lindé (2009) argues that the RBC model also can generate falling hours in response to a positive TFP shock, namely, when allowing for a persistent shock to the growth rate of TFP.

${ }^{15}$ Details from this analysis were included in an earlier version of this paper and are now available from the authors upon request.
} 
must at best be interpreted with great caution. In contrast, the textbook RANK model with sticky prices and wages performs well from the perspective studied here, but of course this conclusion too is subject to the caveat that richer RANK models with wage rigidity may not inherit this property. For all these reasons, we would welcome further investigation into 2-agent versions of richer NK models.

Obviously, we are also interested in the performance of full-fledged models of inequality of the Aiyagari/Huggett kind and indeed the motivation behind the present paper was to help this kind of research along by focusing on specific challenges that need to be addressed. It can, of course, be that the richer inequality settings per se help resolve the difficulty facing the NK model with price rigidity only. Investigations in this direction, i.e., of "true" HANK models, are obviously on the agenda of a number of other researchers and they are on our agenda too. 


\section{References}

Ascari, G., Colciago, A., and Rossi, L. (2016). Limited Asset Market Participation and Optimal Monetary Policy. mimeo.

Auclert, A. (2015). Monetary Policy and the Redistribution Channel. mimeo.

Basu, S., Fernald, J. G., and Kimball, M. S. (2006). Are Technology Improvements Contractionary? American Economic Review, 96(5):1418-1448.

Bilbiie, F. O. (2008). Limited asset markets participation, monetary policy and (inverted) aggregate demand logic. Journal of Economic Theory, 140(1):162-196.

Boppart, T. and Krusell, P. (2016). Labor Supply in the Past, Present, and Future: A Balance-Growth Perspective.

Buffie, E. F. (2013). The Taylor principle fights back, Part I. Journal of Economic Dynamics and Control, 37(12):2771-2795.

Christiano, L. J. and Eichenbaum, M. (2005). Nominal Rigidities and the Dynamic Effects of a Shock to Monetary Policy. Journal of Political Economy, 113(1):1-45.

Christiano, L. J., Eichenbaum, M., and Rebelo, S. (2011). When Is the Government Spending Multiplier Large? Journal of Political Economy, 119(1):78-121.

Christiano, L. J. and Evans, C. L. (1997). Sticky price and limited participation models of money: A comparison. European Economic Review, 41(1997):1201-1249.

Erceg, C. J., Henderson, D. W., and Levin, A. T. (2000). Optimal Monetary Policy with staggered Wage and Price Contracts. Journal of Monetary Economics, 46.

Francis, N. and Ramey, V. A. (2005). Is the technology-driven real business cycle hypothesis dead? Shocks and aggregate fluctuations revisited. Journal of Monetary Economics, 52(8):1379-1399.

Galí, J. (1999). Technology, Employment, and the Business Cycle: Do Technology Shocks Explain Aggregate Fluctuations? American Economic Review, 89(1).

Galí, J. (2009). Monetary Policy, Inflation, and the Business Cycle: An Introduction to the New Keynesian Framework. Princeton University Press. 
Galí, J. and Rabanal, P. (2004). Technology Shocks and Aggregate Fluctuations: How Well Does the Real Business Cycle Model Fit Technology Shocks and Aggregate Fluctuations. NBER Macroeconomics Annual 2004, 19(April).

Gornemann, N., Kuester, K., and Nakajima, M. (2016). Doves for the rich, hawks for the poor? Distributional consequences of monetary policy. mimeo.

Kaplan, G., Moll, B., and Violante, G. L. (2016). Monetary Policy According to HANK. mimeo.

Karabarbounis, L. and Neiman, B. (2014). The Global Decline of the Labor Share. The Quarterly Journal of Economics, pages 61-103.

King, R. G., Plosser, C. I., and Rebelo, S. T. (1988). Production, growth and business cycles. Journal of Monetary Economics, 21(2-3):195-232.

Kuhn, M. and Rios-Rull, J.-V. (2016). Federal Reserve Bank of Minneapolis. Federal Reserve Bank of Minneapolis Quarterly Review, (February).

Lindé, J. (2009). The effects of permanent technology shocks on hours: Can the RBCmodel fit the VAR evidence? Journal of Economic Dynamics and Control, 33(3):597-613.

Lorenzoni, G. (2009). A Theory of Demand Shocks. American Economic Review, 99(5):2050-2084.

McKay, A., Nakamura, E., and Steinsson, J. (2015). The Power of Forward Guidance Revisited. mimeo.

Piketty, T. and Zucman, G. (2015). Wealth and Inheritance in the Long Run, volume 2. Elsevier B.V., 1 edition.

Saez, E. and Zucman, G. (2016). Wealth Inequality in the United States since 1913: Evidence from Capitalized Income Tax Data. Quarterly Journal of Economics, 131(May):519-578.

Schmitt-Grohé, S. and Uribe, M. (2003). Closing small open economy models. Journal of International Economics, 61(1):163-185.

Walsh, C. E. (2014). Workers, Capitalists, Wages, and Employment. mimeo. 
Werning, I. (2012). Managing a Liquidity Trap: Monetary and Fiscal Policy. mimeo.

Wolff, E. N. (2014). Household Wealth Trends in the United States, 1983-2010. Oxford Review of Economic Policy, 30(1):21-43. 